\title{
Corrigendum: Impact of Resistance to Fluconazole on Virulence and Morphological Aspects of Cryptococcus neoformans and Cryptococcus gattii Isolates
}

\section{OPEN ACCESS}

Edited by:

Marcio L. Rodrigues,

Oswaldo Cruz Foundation, Brazil

Reviewed by: Leonardo Nimrichter,

Federal University of Rio de Janeiro,

Brazil

*Correspondence: Ana M. Fusco-Almeida

almeidaf@fcfar.unesp.br

Specialty section: This article was submitted to Fungi and Their Interactions,

a section of the journal

Frontiers in Microbiology

Received: 09 March 2016 Accepted: 01 April 2016

Published: 22 April 2016

Citation:

Rossi SA, Trevijano-Contador N, Scorzoni L, Mesa-Arango AC, de Oliveira HC, Werther K, de Freitas

Raso T, Mendes-Giannini MJS, Zaragoza $O$ and Fusco-Almeida AM

(2016) Corrigendum: Impact of

Resistance to Fluconazole on Virulence and Morphological Aspects

of Cryptococcus neoformans and

Cryptococcus gattii Isolates.

Front. Microbiol. 7:537

doi: 10.3389/fmicb.2016.00537
Suélen A. Rossi ${ }^{1}$, Nuria Trevijano-Contador ${ }^{2}$, Liliana Scorzoni ${ }^{1}$, Ana C. Mesa-Arango ${ }^{3}$, Haroldo C. de Oliveira ${ }^{1}$, Karin Werther ${ }^{4}$, Tânia de Freitas Raso ${ }^{5}$, Maria J. S. Mendes-Giannini ${ }^{1}$, Oscar Zaragoza ${ }^{2}$ and Ana M. Fusco-Almeida ${ }^{1 *}$

${ }^{1}$ Laboratório de Micologia Clínica e Núcleo de Proteômica, Faculdade de Ciências Farmacêuticas, Universidade Estadual Paulista Júlio Mesquita Filho, Araraquara, Brazil, ${ }^{2}$ Unidad de Micología, Centro Nacional de Microbiología, Instituto de Salud Carlos III, Majadahonda, Spain, ${ }^{3}$ Department of Dermatology Research, Universidad de Antioquia, Medellin, Colombia, ${ }^{4}$ Departamento de Patologia Veterinária, Faculdade de Ciências Agrárias e Veterinárias FCAVIUNESP, Universidade Estadual Paulista, São Paulo, Brazil, ${ }^{5}$ Departamento de Patologia, Faculdade de Medicina Veterinária e Zootecnia, Universidade de São Paulo, São Paulo, Brazil

Keywords: Cryptococcus spp., resistance, fluconazole, virulence, Galleria mellonella

\section{A corrigendum on}

Impact of Resistance to Fluconazole on Virulence and Morphological Aspects of Cryptococcus neoformans and Cryptococcus gattii Isolates

by Rossi, S. A., Trevijano-Contador, N., Scorzoni, L., Mesa-Arango, A. C., de Oliveira, H. C., Werther, K., et al. (2016). Front. Microbiol. 7:153. doi: 10.3389/fmicb.2016.00153

Due to an oversight on our part the affiliation of author Karin Werther is incorrect. The correct affiliation is: Faculdade de Ciências Agrárias e Veterinárias FCAV/UNESP, Departamento de Patologia Veterinária, Universidade Estadual Paulista, Jaboticabal, Brazil.

The authors apologize for this mistake. The correction does not affect the scientific validity of the results.

\section{AUTHOR CONTRIBUTIONS}

All authors listed, have made substantial, direct, and intellectual contribution to the work, and approved it for publication.

Conflict of Interest Statement: The authors declare that the research was conducted in the absence of any commercial or financial relationships that could be construed as a potential conflict of interest.

Copyright (® 2016 Rossi, Trevijano-Contador, Scorzoni, Mesa-Arango, de Oliveira, Werther, de Freitas Raso, Mendes-Giannini, Zaragoza and Fusco-Almeida. This is an open-access article distributed under the terms of the Creative Commons Attribution License (CC BY). The use, distribution or reproduction in other forums is permitted, provided the original author(s) or licensor are credited and that the original publication in this journal is cited, in accordance with accepted academic practice. No use, distribution or reproduction is permitted which does not comply with these terms. 